\title{
Message from the Organizers
}

We are pleased to announce that the $14^{\text {th }}$ International Conference on Vibration Engineering and Technology of Machinery (VETOMAC XIV) was successfully closed at Instituto Superior Técnico of the University of Lisbon under the joint organization of IDMEC - Institute of Engineering Mechanics, Instituto Superior Técnico, University of Lisbon (IDMEC/IST/UL) and the Department of Civil Engineering, Faculdade de Ciências e Tecnologia, Universidade Nova de Lisboa (DEC/FCT/UNL).

The Scientific Programme consisted of 6 Plenary lectures, around 150 regular presentations and almost 20 poster presentations. Presentations were grouped according to 13 Mini-Symposia and 13 General Conference Topics. The conference was attended by almost 170 participants (including invited speakers) from 34 countries.

The main objective of the conference was to bring together researchers and engineers devoting their work to vibration-related problems in different areas of engineering applications on a common platform.

We strongly believe that VETOMAC XIV had a significant impact on the development of contemporary analytical, numerical and experimental methods in vibration problems, and created an opportunity for opening a forum for discussion and collaboration amongst the participants.

Nuno Maia and Zuzana Dimitrovová

(conference Chairpersons)

\section{Organizing Institutions}

- IDMEC/IST - Institute of Mechanical Engineering/Instituto Superior Técnico

- DEC/FCT - Department of Civil Engineering/Faculdade de Ciências e Tecnologia

\section{Sponsors}

- CGD- Caixa Geral de Depósitos

- Banco BPI

- IST - Instituto Superior Técnico

- CML - City Council of Lisbon (Câmara Municipal de Lisboa)

- EGEAC - Culture in Lisbon

- Museum of Lisbon - Pimenta Palace (Museu de Lisboa - Palácio Pimenta)

- Tourism of Lisbon (Turismo de Lisboa)

- SPECMAN

- Brüel \& Kjær

\section{Supporting Institutions}

- The Vibration Institute of India

- IP, S.A.- Infraestruturas de Portugal (Portuguese Infrastructures)

- GEOSIN geosynthetics

- TENCATE materials that make a difference

- BBF Technology for environment

- Sotecnisol materiais

- LNEC - Laboratório Nacional de Engenharia Civil (National Laboratory of Civil Engineering) 


\section{Organizing Committee}

- Nuno Maia - DEM/IST/UL and IDMEC/IST (Chairperson)

- Zuzana Dimitrovová - DEC/FCT/UNL and IDMEC/IST (Chairperson)

\section{Steering Committee}

- Prof. Jammi Srinivasa Rao (J.S. Rao) AICTE-INAE Distinguished Visiting Professor BMS College of Engineering, Bangalore and Reva University, Bangalore, India

- Prof. Ronald L. Eshleman

Principal adviser of JVET, Technical Director for Training, Vibration Institute, IL, USA

- Prof. José M. Balthazar

Mechanical-Aeronautics Division, Aeronautics Technological Institute (ITA), SP, Brasil

- Prof. Chee Wah Lim

Department of Architecture and Civil Engineering, City University of Hong Kong, Hong Kong, China

- Prof. C. Nataraj

Director of the The Villanova Center for Analytics of Dynamic Systems (VCADS), University of Villanova, PA, USA

\section{- Prof. Romuald Rządkowski}

Head of the Aeroelasticity Department, Institute of Fluid Flow Machinery, Polish Academy of Sciences, Gdansk, Poland

\section{- Prof. Jyoti K. Sinha}

Head of the Dynamics Laboratory, School of Mechanical, Aerospace and Civil Engineering (MACE), The University of Manchester, Manchester, UK

\section{Invited Lectures}

This world is full of vibrations

\section{J.S. Rao (delivered by Romuald Rzadkowski*)}

Active vibration suppression: Nonlinearity and aeroelastic problems John E Mottershead*

Complex dynamics of drill-string: Theory and experiments

\section{Marian Wiercigroch*, Krishnan Nandakumar, Marcin Kapitaniak and Vahid Vaziri}

Projection methods for stochastic structural dynamics

Sondipon Adhikari ${ }^{*}$, Sion Eilir Pryse and Abhishek Kundu

Vibration based diagnostics and prognostics of defects in rotating machinery

\section{Nataraj*}

Vibration: An excellent plant maintenance tool Jyoti K. Sinha* 


\section{Scientific Committee}

Douglas E. Adams, Vanderbilt University, USA

Sondipon Adhikari, Swansea University, UK

José M. Balthazar, Aeronautics Technological Institute, SP, Brasil

Walter Bartelmus, Wroclaw University of Technology, Poland

Sanjin Braut, University of Rijeka, Croatia

Steven Chatterton, Politecnico di Milano, Italy

Ashish K. Darpe, Indian Institute of Technology Delhi, India

Geert Degrande, Katholic University of Leuven, Belgium

Zuzana Dimitrovová, Nova University of Lisbon, Caparica, Portugal

Régis Dufour, INSA, Lyon, France

Mohamed El Badaoui, Jean Monnet University, France

Ronald L. Eshleman, Vibration Institute, IL, USA

Michael I. Friswell, Swansea University, UK

Mergen H. Ghayesh, University of Adelaide, Adelaide, Australia

Fengshou Gu, University of Huddersfield, UK

Wolfgang Hahn, EDF Energy, London, UK

Tianjian Ji, University of Manchester, UK

Dani Juričić, Jozef Stefan Institute, Slovenia

Piotr Koziol, Cracow University of Technology, Krakow, Poland

Arthur W. Lees, Swansea University, UK

Chee Wah Lim, City University of Hong Kong, Hong Kong, China

Nuno Maia, University of Lisbon, Lisbon, Portugal

Cristinel Mares, Brunel University, London, UK

Traian Mazilu, Universitatea Politehnica

Bucuresti, Romania

David U. Mba, London South Bank University, UK

Guang Meng, Shanghai Jiao Tong University, China
Andrei V. Metrikine, Delft University of Technology, The Netherlands

Amiya R. Mohanty, Indian Institute of Technology Kharagpur, India

John Mottershead, University of Liverpool, UK Prasanna M. Mujumdar, Indian Institute of Technology, Bombay, India

Jiři Náprstek, The Institute of Theoretical and Applied Mechanics, Czech Republic

C. Nataraj, Villanova University, USA

Huajiang Ouyang, University of Liverpool, UK

Zhi Ke Peng, Shanghai Jiao Tong University, China

Evgeny P. Petrov, University of Sussex, UK

Robert B. Randall, University of New South Wales, Australia

J.S. Rao, Reva University, Bangalore, India

Romuald Rządkowski, Polish Academy of

Sciences, Gdansk, Poland

Jerzy T. Sawicki, Cleveland State University, USA

A.S. Sekhar, Indian Institute of Technology Madras, India

Alok Sinha, Pennsylvania State University, USA

Jyoti K. Sinha, University of Manchester, Manchester, UK

Michaël Steenbergen, Delft University of Technology, The Netherlands

Rajiv Tiwari, Indian Institute of Technology, Guwahati, India

Marian Wiercigroch, University of Aberdeen, UK Ye Ping Xiong, University of Southampton, UK Jong-Dar Yau, Tamkang University, New Taipei City, Taiwan

Jaroslav Zapoměl, VSB-Technical University of Ostrava, Czech Republic

Radoslaw Zimroz, KGHM CUPRUM, Wroclaw, Poland 


\section{List of General Conference Topics}

- TP1: Non-linear vibrations

- TP2: Fluid structure interaction

- TP3: Vibration in energy and power systems

- TP4: Machinery and structural dynamics

- TP5: Rotor dynamics

- TP6: Condition monitoring, tip-timing, experimental techniques

- TP7: Composites and nano-structures

- TP8: Microturbines

- TP9: Vehicle dynamics

- TP10: Vibration and waves

- TP11: MEMS, smart structures and systems

- TP12: Structural health monitoring

- TP13: Wave propagation

\section{List of Mini-Symposia}

- BD: Bridge Dynamics Izabela J. Drygała

- DS: Dynamic Stability, Deterministic, Chaotic and Random Post-Critical States Jiří Náprstek

- EH: Energy Harvesting from Ambient Mechanical Oscillations Grzegorz Litak, Daniil Yurchenko

- $\quad$ FV: Lessons in Floor Vibrations: New Design and Retrofit Erin Kelly, Melissa W.Y. Wong, Elisabeth Malsch, Marguerite Pinto

- ML: Vibration of Solids and Structures under Moving Loads Piotr Koziol, Zuzana Dimitrovová

- NC: Nonlinear Dynamics and Control of Engineering Systems Marian Wiercigroch, Marcin Kapitaniak, Vahid Vaziri

- ND: Nonlinear Dynamics, Chaos and Control of Elastic Structures José M. Balthazar, Paulo B. Gonçalves, Pedro L. Ribeiro

- RM: Sustainable Railway Maintenance Simona Fontul, Madalena Barroso, Paula Couto

- RV: Road and Railway Noise and Vibrations: Numerical Modeling and Mitigation Paulo A. Mendes, Luís Godinho, Pedro A. Costa

- SM: Structural Modifications: Modelling Predictions and Experimental Assessment Tiago Silva, Marta Carvalho, António Urgueira, Cristinel Mares

- VE: Simulation and/or Virtual Experiments for Vehicle Vibro-Acoustic Response Miguel Matos Neves

- VM: Vibration Evaluation, Control and Mitigation on Civil Engineering Structures Maria J.F. Silva, Hugo Rodrigues

- VS: Vibration Problems in Strongly Nonlinear Mechanical Dissipative Systems Alexey A. Kireenkov, Sergey I. Zhavoronok 